\title{
Some effects of cerebellar stimulation
}

\section{DAVID ASDOURIAN and KATHRYN \\ FRERICHS, Wayne State University, Detroit, Mich. 48202}

Rats were tested for approach and escape to cerebellar stimulation. None of the quantitative measures taken indicated that the stimulation was either rewarding or aversive. Face washing, face quivering, and freezing were observed during the escape trials, suggesting that the stimulation may not have been altogether neutral.

Cerebellar stimulation has been used extensively in electrophysiological research and especially in work concerned with motor systems, but there is virtually no work cited in the literature dealing explicitly with the psychological effects of cerebellar stimulation. Thus, for example, it is not known if stimulation of any part of the cerebellum is rewarding or aversive. The most widely held assumption has been that the cerebellum is psychologically silent so that any neural activity originating in the cerebellum gets its work done on an unconscious level. The only study that the authors could find touching directiy on this problem was done by Brogden \& Gantt (1942). They demonstrated that faradic stimulation of the cerebellum (lobulus ansiformis of the dog) could be used effectively as an unconditioned stimulus in classical conditioning experiments. Because of the theoretical issues that Brogden and Gantt were concerned with, they paid close attention to the emotional behavior of their animals when the faradic shock was administered. They reported that no emotionality could be detected. Their study is suggestive but not conclusive concerning possible motivational effects of cerebellar stimulation since Ss were not permitted the option of approaching, escaping, or avoiding the stimulation. Probably no one study could determine conclusively that the cerebellum was motivationally neutral. Such a conclusion would gain strength only on the basis of converging work from a number of laboratories.

The present research was designed to study approach through the use of self-stimulation procedures and to study aversion, using a shuttlebox.

\section{SUBJECTS}

Nine animals were chronically implanted with bipolar electrodes (Plastic Products Company, Roanoke, Virginia, No. 303-018-312). They were approximately 110 days old at the time of surgery.

\section{EXPERIMENT 1}

\section{Apparatus}

The Skinner box in which Ss were tested for self-stimulation is described elsewhere (Asdourian, Stutz, \& Rocklin, 1966). Procedure

Sixty-cycle ac brain shock was monitored through a Hunter timer so that each $S$ received a maximum of $0.4 \mathrm{sec}$ of stimulation for any one bar press. When this maximum was reached, Ss had to release the bar and press again in order to receive more stimulation. If $\mathrm{S}$ kept the bar depressed for less than $0.4 \mathrm{sec}$, he received a shock that terminated with release of the bar. Each $S$ was started at a current of 20 microamps RMS. On Day 1 , Ss were shaped for $10 \mathrm{~min}$ by the E. Each time an $S$ approached the bar, $E$ pushed the bar from outside the box, thus stimulating $S$. This shaping procedure was carried on for 2 days. Starting with the 3 rd day, Ss were shaped for $2 \mathrm{~min}$ and then run for $10 \mathrm{~min}$ each day on a free-operant basis. The $2 \mathrm{~min}$ of shaping always preceded the $10-\mathrm{min}$ free run. All animals were given free access to the bar at a given current level for 5 days. Following the 5 -day run at 20 microamps, Ss were shaped again for $10 \mathrm{~min}$ a day for 2 days at 40 microamps and then run for 5 days at this new level. The original plan had been to repeat this procedure, increasing current levels by 20 -microamp steps up to 80 microamps, followed by increases of 40 microamps up to a maximum of 160 microamps. In fact, when an animal displayed forced movement, he was discontinued. So, for example, S 16 showed forced movement over 40 microamps and was discontinued at that level. Since S 18 showed forced movement in the range between 90 and 120 microamps, he was run for 5 days at 80 microamps and for 5 more days at 85 microamps, which was the highest level at which no forced movement was apparent (inadvertently, Ss were run 6 days Table

Showing Electrode Placements, Current Levels, Individual Mean Number of Responses Over Five 10-Min Sessions at Each Current Level, and the Mean Number of Responses Across Ss

\begin{tabular}{|c|c|c|c|c|c|c|c|c|}
\hline \multirow{2}{*}{$\begin{array}{l}\text { Subject } \\
\text { No. }\end{array}$} & \multirow{2}{*}{$\begin{array}{l}\text { Electrode } \\
\text { Placements }\end{array}$} & \multicolumn{7}{|c|}{ Current Levels in Microamperes } \\
\hline & & 20 & 40 & 60 & 80 & 85 & 120 & 160 \\
\hline 11 & $\begin{array}{l}\text { Ventral lobule } \\
\text { of culmen }\end{array}$ & 0.60 & 0.80 & 1.83 & 0.20 & & 0.40 & 1.00 \\
\hline 17 & $\begin{array}{l}\text { Ventral lobule } \\
\text { of culmen }\end{array}$ & 1.20 & 2.20 & 3.00 & 4.40 & & 4.60 & 1.00 \\
\hline $\begin{array}{l}12 \\
16\end{array}$ & $\begin{array}{l}\text { Superior peduncle } \\
\text { Superior peduncle }\end{array}$ & $\begin{array}{l}1.20 \\
1.60\end{array}$ & $\begin{array}{l}0.80 \\
0.00\end{array}$ & 4.50 & 4.20 & & 4.40 & 2.80 \\
\hline 13 & Sublobule IIIa & 8.40 & 5.40 & 4.00 & 2.40 & & 1.60 & 6.60 \\
\hline 19 & Sublobule IIIa & 0.00 & 0.20 & 0.17 & 0.40 & & 0.40 & 0.20 \\
\hline 15 & Ventral lobule CII & 0.60 & 0.00 & 0.17 & 0.40 & & & \\
\hline 14 & Ventral lobule Cll & 0.40 & 0.80 & 0.17 & & & & \\
\hline 18 & Nucleus interpositus & 1.40 & 2.00 & 3.00 & 3.00 & 3.00 & & \\
\hline \multicolumn{2}{|c|}{$\begin{array}{l}\text { Mean number of responses } \\
\text { across Ss }\end{array}$} & 1.69 & 1.37 & 2.10 & 3.00 & 3.00 & 2.28 & 2.32 \\
\hline
\end{tabular}
electrode placements.

Histology

The histology was performed after the completion of Experiment 2 by perfusing Ss with $10 \%$ formalin, embedding the brains in celloidin, cutting the sections at 50 microns, collecting every other section around the locus of the electrode track and staining with cresyl fast violet. The electrode placements were confirmed by referring to the Pellegrino \& Cushman (1967) atlas.

\section{Results and Conclusions}

The response rates shown in Table 1 clearly represent operant levels of bar pressing. The highest mean rate achieved by $\mathrm{S} 13$ at 20 microamps would be a borderline "self-stimulator," but the raw data for S 13 showed that this mean level was achieved because he made 26 responses on 1 day. On the other 4 days, he pressed $0,3,7$, and 6 times. Observation of all Ss, including $S 13$, revealed that bar pressing was always done in the course of sniffing about the box and was directly related to the amount of generalized activity that an $S$ engaged in. There were none of the sustained periods typical of self-stimulating Ss when they stayed next to the bar and responded. Given these low response rates, together with the random nature of the Ss' behavior, one must come to the most parsimonious conclusion that cerebellar stimulation at these sites is not rewarding. EXPERIMENT 2

In the second part of this study, the same nine Ss run in Experiment 1 were tested in a shuttlebox to determine if cerebellar shock was aversive in nature. The shuttlebox in which animals were tested for escape was $8 \times 24 \times 26$ in. high. It contained a brain shock circuit identical to the one used in the self-stimulation box. The box was separated into two equal-sized compartments by a Masonite barrier, 1 in. high. Thus, Ss could escape cerebellar

instead of 5 days at 60 microamps). Table 1 summarizes the results of Experiment 1 and includes the current levels at which Ss were run and the . 
shock by moving from one compartment to the other.

\section{Procedure}

Since from 10 days to 30 days had elapsed between the last day of testing in Experiment 1 and the 1 day of testing in Experiment 2, Ss were checked again for forced movement in the event that thresholds might have changed. A comparison of Tables 1 and 2 shows that some changes did take place. In this part of the study, all Ss were run at current levels just below forced movement thresholds. Ss were placed into the apparatus and run 60 trials in one session. For each trial, the 60 -cycle ac brain shock was pulsed $0.4 \mathrm{sec}$ on, and $0.6 \mathrm{sec}$ off. The stimulation was kept on for a maximum of $30.0 \mathrm{sec}$ or until $S$ crossed over the barrier to the other side of the shuttlebox. Intertrial intervals lasted 15,30 , and $45 \mathrm{sec}$, were randomized, and had a mean of $30 \mathrm{sec}$. If an $S$ crossed the barrier during the intertrial interval, the new trial was started on the side that $S$ happened to choose.

\section{RESULTS AND CONCLUSIONS}

The first item of interest in Table 2 is the mean latencies for each $S$ over 60 trials. If these latencies are compared with the escape latencies obtained by Roberts (1958) from cats that received aversive hypothalamic stimulation, one sees that with hypothalamic stimulation initial escape latencies may be high, but that within 10-15 trials, latencies fall below $5 \mathrm{sec}$ (even for animals that do not subsequently learn to avoid). The mean latencies in the present study averaged over Ss for each 10-trial block were 25.0, 26.7, $26.8,28.0,27.2$, and $27.9 \mathrm{sec}$. On this basis, the present data do not qualify as escape data. Remembering that a trial with pulsing cerebellar shock lasted a maximum of $30.0 \mathrm{sec}$, one sees that six of the nine Ss (Nos. 11, 14, 15, 16, 17, 18) stayed in one compartment during virtually the whole experiment. Ss 15 and 17 did show small flurries of intertrial crossings, but these occurred sporadically, were sometimes double or triple crossings, and were not consistently oriented either toward or away from the side on which they last received shock. The other three Ss (Nos. $12,13,19)$ were more active both during trials and between trials (Table 2), but even among these three $\mathrm{Ss}$ the lowest mean latency was $18.7 \mathrm{sec}$, suggesting that the stimulation was not aversive.

The mean number of intertrial crossings was 6.7 for the first 30 trials and 4.8 for the last 30 trials. This difference was not significant, but even if it were, it could simply reflect the Ss' habituation to the apparatus.

Contrary to what one would expect if the Ss had found the stimulation aversive, the mean latencies for the second half of the trials were either equal to or longer than the mean latencies for the first half. Indeed, the $t$ values for two of the Ss (Nos. $13,15)$ were significant at the .05 level (since electrode placements differed from $S$ to $S$ even to the extent that, e.g., two superior peduncle electrodes were not in the same part of this structure, and, since current levels varied, we did not feel justified in grouping our scores), but the means were in the direction opposite to what one would expect if Ss were learning to become efficient in their escape behavior. One might even be tempted to conclude that the stimulation was rewarding and that Ss learned to stay in one place to receive the shock. This conclusion is not borne out, however, by the results in Experiment 1. Such a conclusion would be especially unwarranted here since none of the nine Ss followed the shock from one side of the box to the other.

On the basis of these findings, then, one must conclude that the cerebellar sites tested above instigate neither approach nor aversive behavior when electrically stimulated. At least such behaviors are not discernible when using conventional measures of the kind described here. These results confirm the conclusions arrived at by Brogden and Gantt concerning the absence of motivational consequences of cerebellar stimulation. The present data extend these conclusions to cover a

\section{Table 2}

Showing Electrode Placements, Current Levels, Individual Mean "Escape" Latencies for the First and Last 30 Trials, $t$ Values and p Values Derived from Comparing the Latencies for the First 30 Trials Against Those of the Second 30 Trials, and the Total Number of Intertrial Crossings for Each S

\begin{tabular}{|c|c|c|c|c|c|c|c|}
\hline \multirow[b]{2}{*}{$\begin{array}{c}\text { Subject } \\
\text { No. }\end{array}$} & \multirow[b]{2}{*}{ Electrode Placements } & \multirow[b]{2}{*}{ Current } & \multicolumn{2}{|c|}{$\begin{array}{c}\text { Mean Escape } \\
\text { Latencies in Sec } \\
\end{array}$} & \multirow[b]{2}{*}{$t$} & \multirow{2}{*}{ p } & \multirow{2}{*}{$\begin{array}{c}\text { Total } \\
\text { Intertrial } \\
\text { Crossings }\end{array}$} \\
\hline & & & $\begin{array}{l}\text { Trials } \\
1-30\end{array}$ & $\begin{array}{c}\text { Trials } \\
31-60\end{array}$ & & & \\
\hline 11 & Ventral lobule of culmen & 160 & 30.0 & 30.0 & 0.00 & n.s. & 0 \\
\hline 17 & Ventral lobule of culmen & 160 & 28.9 & 30.0 & 1.35 & n.s. & 16 \\
\hline 12 & Superior peduncle & 160 & 19.7 & 20.3 & 0.20 & n.s. & 31 \\
\hline 16 & Superior peduncle & 30 & 30.0 & 30.0 & 0.00 & n.s. & 3 \\
\hline 13 & Sublobule IIla & 160 & 19.6 & 25.2 & 2.31 & $<.05$ & 24 \\
\hline 19 & Sublobule IIIa & 160 & 18.7 & 23.8 & 1.83 & n.s. & 21 \\
\hline 14 & Ventral lobule CII & 50 & 30.0 & 30.0 & 0.00 & n.s. & 0 \\
\hline 15 & Ventral lobule CII & 55 & 26.7 & 30.0 & 2.33 & $<.05$ & 7 \\
\hline 18 & Nucleus interpositus & 85 & 30.0 & 30.0 & 0.00 & n.s. & 2 \\
\hline
\end{tabular}

number of deep structures in the cerebellum and to apply to the rat as well as to the dog.

Three forms of behavior that we observed in some Ss to a more or less degree, but were not prepared to measure quantitatively, have been cited frequently as indices of emotionality in rats. Ss 11 and 19 displayed vigorous grooming (face washing) during most of the trials and intertrials. S 13 groomed only during Trial 51, and he also exhibited a facial quivering reminiscent of teeth chattering during Trial 56: S 12 exhibited facial quivering during Trials 54 and 55 . The quivering stopped when the shock was turned off. The fact that the quivering occurred rarely suggests that the shock was only indirectly responsible for its appearance and that it may have been an emotional response to the stimulation rather than a forced move elicited by efferent cerebellar activity. The grooming may have been a reflection of emotionality, but even so, one cannot be sure that it was not simply the result of the S's exposure to a novel environment without some other confirming index (such as escape).

Much more prevalent than grooming or quivering was freezing. This last behavior consisted of an $S$ huddling very quietly in some part of the box throughout most of the experiment. These Ss were probably not forced into this freeze by the stimulation (in the sense that the stimulation directly paralyzed muscles), since the same $S$ frequently huddled through a number of trials and intertrials and then began to sniff about and begin grooming through subsequent trials. Although freezing has been frequently suggested as an index of fear, we cannot be sure that such an interpretation is appropriate here (especially since none of our animals were motivated to learn a simple escape task).

Given the anatomical intimacy of the cerebellum with the rest of the nervous system, it is worth some effort by researchers to discover the extent to which it may participate in psychological processes.

\section{REFERENCES}

ASDOURIAN, D., STUTZ, R. M., \& ROCKLIN, K. W. Effects of thalamic and limbic system lesions on self-stimulation. Journal of Comparative \& Physiological Psychology, $1966,61,468-472$.

BROGDEN, W. J., \& GANTT, W. H. Intraneural conditioning: Cerebellar conditioned reflexes. Archives of Neurology \& Psychiatry, 1942, 48, 437-455.

PELLEGRINO, L. J., \& CUSHMAN, A. J. $A$ stereotaxic atlas of the rat brain. New York: Appleton-Century-Crofts, 1967.

ROBERTS, W. W. Rapid escape learning without avoidance learning motivated by hypothalamic stimulation in cats. Journal of Comparative \& Physiological Psychology, 1958, 51, 391-399. 